\title{
Measurement of Gust Response on a Turbine Cascade
}

\author{
A.P. Kurkov and B.L. Lucci \\ Lewis Research Center \\ Cleveland, Ohio
}

Prepared for the

Turbo Expo ' 95

sponsored by The American Society of Mechanical Engineers

Houston, Texas, June 5-8, 1995
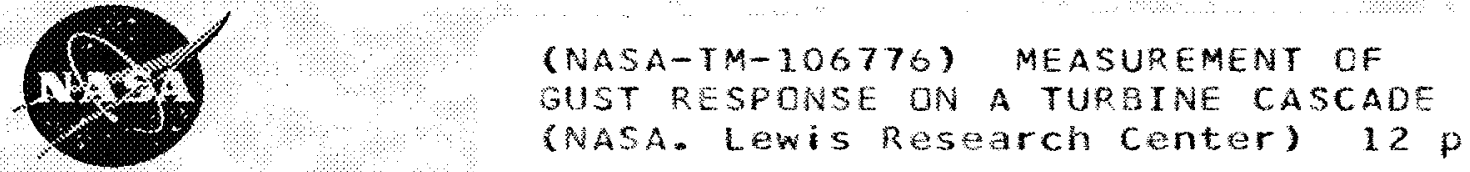


\title{
MEASUREMENT OF GUST RESPONSE ON A TURBINE CASCADE
}

\author{
A. P. Kurkov and B. L. Lucci \\ National Aeronautics and Space Administration \\ Lewis Research Center \\ Cleveland, Ohio
}

\begin{abstract}
The paper presents benchmark experimental data on a gust response of an annular turbine cascade. The experiment was particularly designed to provide data for comparison with the results of a typical linearized gust-response analysis. Reduced frequency, Mach number, and incidence were varied independently. Except for the lowest reduced frequency, the gust velocity distribution was nearly sinusoidal. For the high inlet-velocity series of tests, the cascade was near choking. The mean flow was documented by measuring blade surface pressures and the cascade exit flow. High-response pressure transducers were used to measure the unsteady pressure distribution. Inlet-velocity components and turbulence parameters were measured using hot wire. In addition to the synchronous time-average pressure spectra, typical power spectra are included for several representative conditions.
\end{abstract}

\section{INTRODUCTION}

In recent years there has been a renewed interest in theoretical and experimental treatments of the gust response mainly to provide better tools and foundations for predicting unsteady forces on turbomachinery blades. For the current state-of-the-art in the field the reader is referred to the paper by Manwaring and Wisler (1993). They conducted a series of experiments in a large, low-speed facility. The experiments provided aerodynamic forced-response measurements on a compressor stator and a turbine nozzle, and included the measurement of gust inlet-velocity profiles. The excitation was provided by the rotor wakes and a rotating distortion. However, experimental data are still needed in a transonicflow regime where most of the current turbomachinery operates. It is known that transonic effects are important in flutter phenomena (see for example Kurkov and Mehmed, 1993), and hence, it is expected that they will also be significant for the forced excitation.

The object of the current experiment is to fill this gap and to provide systematic variation of several key parameters which should help the evaluation of the gust analyses. In order to conform to the usual assumptions made in the frequencydomain analyses, the wake-generating rotor and the turbine cascade were widely separated and the gust was nearly sinusoidal ( for majority of the tests) and of small amplitude. Note that the nature of the disturbance in this experiment is vorticial, and the data, therefore, represent a response to this type of gust.

This paper is only concerned with detailed presentation of experimental data. A follow-up paper will include detailed comparisons with analytical results obtained using a linearized two-dimensional code that is based on a potential steady-flow solution and includes inviscid-viscous interaction. The article series will be completed by presenting structural-response data and analysis.

\section{TEST FACILITY}

The air entered the bellmouth and passed through the annulus to the rotor consisting of radial pins, either 0.317 or $0.476 \mathrm{~cm}$ (1/8 or $3 / 16$ inches) in diameter. The wakes from the pins were convected by the main flow into a turbine cascade. The rotor pins and the turbine cascade are depicted in Fig. 1. The rotor induced a swirl of $3^{\circ}$ to $5^{\circ}$ into the mean flow. The direction of rotation determined the sign of the swirl component, which provided a convenient way of changing the flow incidence. Nominally, the flow into the cascade was axial. For the current experiment, cascade turning angle was $61^{\circ}$, the blade chord angle relative to the axial was $38^{\circ}$, and the distance between the rotor and the cascade leading edge was 3.9 axial chords. The chord length was $6.35 \mathrm{~cm}$, the axial chord was $4.75 \mathrm{~cm}$, and annulus outside and inside diameters were 40.64 and 27.13 
$\mathrm{cm}$ respectively. The cascade consisted of 23 blades that extended in the radial direction spanning the annulus.

The power was delivered to the rotor through a long shaft that extended vertically through the inner pipe of the annulus. The shaft exits the outer pipe at the $90^{\circ}$ bend close to the floor level and is terminated by a belt driven pulley which transmits the power from the electric motor.

\section{TEST MATRIX}

The number of pins on the rotor was either 24,12 , or 6 . The pin diameter for 24-pin configuration was $0.317 \mathrm{~cm}$ and for 12- and 6-pin configurations it was $0.476 \mathrm{~cm}$. The pin diameter was increased for the last two configurations in order to reduce the number of harmonics in the wake. The reduced frequency,

$$
\omega=\frac{N_{w} \omega_{r} c_{h}}{U_{1}}
$$

was varied by changing the number of pins on the rotor, $\mathrm{N}_{\mathrm{w}}$. In this equation, the shaft angular velocity is denoted by $\omega_{\mathrm{r}}$, the blade chord by $c_{h}$, and the axial inlet velocity by $U_{1}$. Subscript 1 denotes the station downstream of the bellmouth and upstream of the rotor. In subsequent sections, subscripts 2 and 3 denote the station downstream of the rotor and upstream of the cascade, and the station downstream of the cascade, respectively. Substituting the value for the blade cord, this equation can be expressed as

$$
\omega=0.375 \frac{N_{w}}{\phi}
$$

where $\phi$ is the flow coefficient, defined as the ratio of axial inlet velocity to the rotational velocity at midspan rotor radius. Throughout the test the flow coefficient was kept constant at 0.9 . Thus, for the available $\mathrm{N}_{\mathrm{w}}$ 's, the reduced frequency values were, 10, 5, and 2.5. The inlet Mach number was either 0.2 or 0.27 . At the higher inlet Mach number the flow in the blade passage throat was near choking at the midspan radius. To maintain the desired flow coefficient, the shaft speeds for these two Mach numbers were on the average 4290 and $5790 \mathrm{rpm}$. The Reynolds numbers corresponing to low and high inlet velocities were $2.7 \times 10^{5}$ and $3.6 \times 10^{5}$, based on blade chord.

Positive and negative values of incidence corresponded to two directions of rotation. Because of the inlet-flow symmetry relative to axial direction, it was sufficient to survey the wake for only one direction of rotation. The incidence values were between $3^{\circ}$ and $5^{\circ}$ and depended mainly on the rotor pin diameter. Numerical incidences in this paper are reported as deviations from the nominal design axial inlet-flow direction.

Note that when changing the direction of rotation, the interblade phase angle also changes the sign. Taking into account the number rotor pins and the number of blades, the interblade phase angles for positive and negative rotations are close to $\pm 360, \pm 180$ or \pm 90 for reduced frequencies of 10,5 , and 2.5 respectively. The last change is the most significant, and, therefore, for reduced frequency of 2.5 the change in incidence is coupled with a substantial change in interblade phase angle.

\section{EXPERIMENTAL MEASUREMENTS}

The inlet condition was defined by the barometric pressure, inlet temperature at the bellmouth inlet, and several static pressure measurements on the inside and outside wall of the annulus downstream of the bellmouth. The cascade exit flow was surveyed at the blade midspan radius over a circumference in excess of one blade pitch with a five-hole probe. This station was one axial chord length downstream of the cascade trailing edge.

The cascade inlet-velocity components at the midspan radius were measured with a hot wire. To simulate the far-field frozen gust condition, the cascade was removed for these measurements, and the inner and outer spacer rings were installed in its place to maintain the same annulus geometry. The hot-wire measurements were made at the axial location corresponding to the cascade leading-edge position.

The single-wire method was implemented essentially as given by Bruun (1990) for the mean velocity and by Fujita and Kovasznay (1968) for the mean-square turbulence velocities. For each wake point, four data runs were obtained corresponding to four different angles of the wire relative to the axial flow direction. (The run reproducibility was well within the measurement accuracy.) Only two wire angles were needed for the mean flow velocity components. For the turbulence velocities, the four wire angles allowed the equations to be solved by the least-square method. Wire calibration was performed in the test facility at the station just downstream of the bellmouth. After the wire was calibrated, it was transferred together with the actuator to the wake measurement station downstream of the rotor. IFA-100 anemometer (TSI Inc.) was used to process hot-wire signals. The analog signals were digitized at 150 or $200 \mathrm{KHz}$ for the low- and high-shaft-speed runs. Prior to calculating mean-square turbulence parameters, the hot wire data were digitally filtered using a 256-point finite impulse response filter (Rabiner and McGonegal, 1979).

The steady-state blade-pressure distribution was measured with a specially instrumented hollow blade provided with 21 surface pressure taps. For the steady-state conditions the flow was axial and the rotor was replaced with spacer rings to preserve the axial geometry. Because the rotor induces a small swirl into the mean flow, this blade was also used for unsteady tests to evaluate the effect of the swirl. Long tubes leading to the transducers eliminated all unsteadiness from the data. Separate transducers were used for each port. They were automatically calibrated in approximately 20-min intervals, identical to the other steady-state transducers.

The dynamic pressures on the blade surfaces were measured by $3.45 \mathrm{~N} / \mathrm{cm}^{2}$ ( $5 \mathrm{psi}$ ) differential transducers manufactured by Kulite Semiconductor Products, Inc., (LQ-125 series). The 
transducers were mounted in a hollow blade at the midspan radius and were recessed slightly from the blade surface. The diameter of the sensitive area was $1.8 \mathrm{~mm}$, and the natural frequency was $70 \mathrm{KHz}$. Because of the high curvature at the leading-edge stagnation point, a smaller transducer (XCS 062) with the sensitive area diameter of $0.71 \mathrm{~mm}$ and the natural frequency of $150 \mathrm{KHz}$ was used at this location. The back sides of the transducers were connected to a reference pressure source, which was selected so that the measured differential pressure was within the transducers limits. A separate reference was used for the transducers on the pressure and the suction sides of the blade. With the instrumented blade installed in the tunnel, the transducer calibration was performed prior to each research run by reducing the pressure to the back sides of the diaphragms below the atmospheric, while maintaining quiescent conditions in the wind tunnel.

The five-hole probe, manufactured by United Sensor \& Control Corporation (prism type, model DA-125), was nulled in the yaw direction. For the pitch angle, and the total and static pressures, the free-jet calibration curves were used.

The steady-state data were acquired using the Central Data Processing Facility, while all dynamic data were recorded locally. A Concurrent 6350 series computer was used to digitize and analyze the data. For pressure signals, 13 channels were acquired simultaneously using a 12-bit digitizer and a sample and hold module. The sampling rate was either 75 or $103 \mathrm{KHz}$, depending on the shaft speed. The unsteady pressure data were filtered at $20 \mathrm{KHz}$ using a 8-pole-6-zero, constantdelay, low-pass filter.

The once-per-revolution signal was generated by a highresponse fiber-optic sensor. The probe, positioned on the outside wall opposite the rotor pins, transmitted the light to and collected the reflected light from a rotating pin that had a polished tip. (The tips of the remaining pins were painted black.) The probe diameter was $3.175 \mathrm{~mm}$ and its frequency response was $150 \mathrm{KHz}$. The probe output, usually between 2 and $4 \mathrm{~V}$, depended on the gap between the probe tip and the pins.

The locations of the steady-state and dynamic ports on the instrumented blades are given in Fig. 2. (Note that separate blades were used for the two measurements.) The dynamic ports are numbered for later reference. Blade and pressure-port coordinates are given in tabular form in the Appendix. The blade coordinates are listed in Table IA in terms of lower (subscript L) and upper (subscript U) contours. The units in this table are inches, as specified in the drawing. The $X$ axis is horizontal and tangent to the two points on the lower surface in Fig. 2, and the $Y$ axis is vertical and tangent to the point $X_{L}=$ $0, Y_{L}=0.192 \mathrm{in}$. If shown, the axis of rotation in Fig. 2 would be tilted $38^{\circ}$ relative to the $\mathrm{X}$ axis (see also Fig.1). The leadingedge radius that completes the contour of the lower surface between the $X$ and $Y$ tangency points is 0.192 in., and the trailing-edge radius is 0.034 in. Tables $\amalg A$ and IIA in the Appendix list the measured $X$ coordinates in inches of the steady-state and dynamic pressure ports (which are also identified by the port number shown in Fig. 2).

The 12-bit digitizer provided sufficiently high dynamic range so that both ac and dc components for the hot wire and the unsteady pressure signals could be captured. An exception was the port 3 pressure transducer (Fig. 2), which had a large dc zero shift and, therefore, had to be ac coupled.

The unsteady signals were digitized to the memory in a contiguous stream that comprised at least 200 revolutions. The data analysis was performed subsequent to the test. This minimized the test time and provided the best accuracy, since test conditions did not have to be maintained over an extended period. The once-per-revolution signal was used to sort the data into the consecutive revolution periods. Because the digitizing rate for all tests was in excess of 1024 points per revolution, 1024 approximately equidistant points could be selected for each revolution. For the spacial time-domain distributions (1024 points), the data were averaged over the total of 200 revolutions; however, for the spectral analyses, the length of the averaged segment was 8 revolutions ( 8192 points) resulting in approximately 25 averages. Thus the resolution for the phasesynchronous spectra was $1 / 8$ engine order $(E)$. For the power spectra, the averaging was performed in the frequency domain resulting in 25 averages for each of the 4096 frequency points. Because the discrete Fourier transforms included an integral number of revolutions and, therefore, in the case of forced response an integral number of cycles, the spectral amplitudes were essentially confined to single-frequency lines. This also made windowing unnecessary.

\section{RESULTS}

\section{Inlet-Velocity Profiles}

Figure 3 presents the unsteady axial (u), and circumferential (v) time-averaged velocity components expressed as percents of inlet velocity $U_{1}$ for the inlet Mach number $M_{1}=0.27$, and the three reduced frequencies of 10,5 , and 2.5 . The results for the inlet Mach number of 0.2 are quite similar. The corresponding synchronously averaged spectral results are presented in Table $I$, where $\beta_{2}$ denotes the incidence in the cascade leading-edge plane. From these results it follows that the gust was nearly sinusoidal for the reduced frequencies of 10 and 5. Amplitudes were larger for the reduced frequencies of 5 and 2. 5, because larger diameter rotor-pins were used for these runs. The incidences for these reduced frequencies were also somewhat higher in magnitude. For the reduced frequency of 2.5 the first two harmonics were significant.

\section{Steady and Mean Pressures}

The steady-state blade pressure distribution was obtained for the axial inlet flow without the rotor and corresponds to $\omega=0$ label in the figures. For the nonzero reduced frequencies, there was a mean incidence present relative to the axial flow direction, which somewhat affected the distribution of the pressure coefficient, 
TABLE I - TIME-AVERAGE INLET-VELOCITY SPECTRA

\begin{tabular}{|c|c|c|c|c|c|c|c|c|c|c|c|c|c|c|}
\hline \multirow[t]{2}{*}{$\omega$} & \multirow[t]{2}{*}{$M_{1}$} & \multirow[t]{2}{*}{$\beta_{2}$} & \multicolumn{6}{|c|}{$\begin{array}{l}\text { Harmonic amplitude (percent) and phase (deg), } \\
u / U_{1}\end{array}$} & \multicolumn{6}{|c|}{$\begin{array}{c}\text { Harmonic amplitude (percent) and phase (deg), } \\
\mathrm{v} / \mathrm{U}_{1}\end{array}$} \\
\hline & & & \multicolumn{2}{|c|}{1} & \multicolumn{2}{|c|}{2} & \multicolumn{2}{|r|}{3} & \multicolumn{2}{|c|}{1} & & \\
\hline \multirow{2}{*}{2.5} & 0.2 & 4.59 & 7.36 & -78.9 & 4.34 & 29.2 & 1.59 & 141.2 & 6.60 & -76.8 & 3.78 & 26.34 & 1.38 & 138 \\
\hline & 0.27 & 5.17 & 7.76 & -69.2 & 5.36 & 55.5 & 2.35 & -178.3 & 5.48 & -58.6 & 3.23 & 57.4 & 1.29 & 178 \\
\hline \multirow{2}{*}{5} & 0.2 & 3.85 & 7.70 & 74.4 & 1.03 & -8.9 & 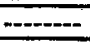 & $\cdots$ & 6.95 & 71.8 & 0.50 & -20.8 & $\cdots$ & ------- \\
\hline & 0.27 & 3.52 & 8.01 & 63.0 & 1.06 & -20.1 & $\cdots$ & 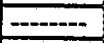 & 8.67 & 65.5 & 1.16 & -31.4 & 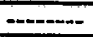 & ----- \\
\hline \multirow{2}{*}{10} & 0.2 & 3.24 & 4.40 & -11.6 & --.-- & $-\ldots$ & $\ldots$ & $\cdots$ & 4.87 & -10.8 & ------- & - - - - & $\ldots$ & - \\
\hline & 0.27 & 2.98 & 4.07 & 8.02 & $-\cdots$ & - & $-\cdots$ & $-\cdots$ & 4.54 & 8.46 & & $-\cdots-\cdots$ & $-\ldots$ & - \\
\hline
\end{tabular}

$$
C_{p}=\frac{p-p_{1}}{\rho_{1} U_{1}^{2} / 2}
$$

where $p$ denotes the static pressure and $\rho$ the density (see Figs. 4 and 5). At the 0.075 chord fraction in Fig. 5 on the pressure surface, the pressure coefficient is reduced for $\omega=10$ relative to other reduced frequencies. (Note that pressure coefficient is negative for positive ordinates.) At the inlet Mach number of 0.27 , in this figure there is also a reduction of pressure coefficient on the suction side of the rear portion of the blade for $\omega=10$. On the other hand, the gust amplitude (Table I) does not appear to be a strong factor for the mean pressure coefficient distributions.

\section{Exit Flow}

The exit-flow station was one axial chord downstream of the cascade trailing edge. The distributions of the yaw and pitch angles for one blade passage are presented in Fig. 6 for the inlet Mach number of 0.27 and the reduced frequency of 10 . Distributions for other reduced frequencies and inlet Mach numbers were quite similar. Figure 7 presents the total pressure plot for the conditions for which the loss was the maximum. The total pressure ratio depended mainly on the Mach number and the reduced frequency.

The exit Mach number distribution exhibited dependance on the inlet Mach number, the incidence, and the reduced frequency, as illustrated in Fig. 8. The differential increase in the exit Mach number for $\omega=10, M_{1}=0.27$, and $\beta_{2}<0$ supports the observed drop in the mean pressure coefficient in the aft portion of the blade on the suction side in Fig. 5.

\section{Unsteady Pressure Spectra}

The first harmonics of synchronously averaged, complex, pressure spectra are presented in Table II. The amplitudes are given in percent of the inlet dynamic pressure (first row for each $\beta_{2}$ ) and phase angles are given in radians (second row). The second and third harmonics for the unsteady pressures were significant for the reduced frequency of 2.5 , just as for the inlet velocity spectra. Thus, for this value of reduced frequency, the time-domain experimental results will be affected, to some extent, by the higher harmonics. In the frequency domain, the amplitudes of the second harmonic for the reduced frequency of 2.5 result in qualitatively similar distribution to that corresponding to the first harmonic for reduced frequency of 5 . The amplitudes for the reduced frequencies of 5 and 2.5 are larger than the amplitude for the reduced frequency of 10 because of the larger rotor pins used for these frequencies. Thus, the results for the reduced frequency of 10 more nearly represent the small amplitude sinusoidal disturbance usually assumed for gust analyses in the frequency domain.

The amplitude distribution in Table II is strongly dependent on the reduced frequency and incidence. Mach number dependence is weak for negative incidences; however, for positive incidences and lower reduced frequencies it is significant. For example, a steep amplitude variation on the suction side of the blade near the leading edge (positions 0,1 , and 3) is present for $M_{1}=0.27, \omega=2.5$, and $\beta_{2}>0$. Since the wavelength of the disturbance is the largest for this reduced frequency, one would not expect such a steep variation in the unsteady-pressure amplitude at this condition. For $M_{1}=0.2$, the amplitude variation is much less at these locations.

The representative root-mean-square (RMS) spectra are illustrated in Fig. 9. The synchronous peaks in these spectra are virtually identical with the corresponding peaks in the timeaverage spectra in Table II; however, they also include the nonsynchronous origin and the random pressure fluctuations. The frequency units are engine orders; thus, the synchronous peaks appear at the frequency equal to the number of rotor pins. The position-axis units correspond to blade port numbers in Fig. 2; thus, position 0 corresponds to the port nearest to the leading edge on the suction surface side, and 11 corresponds to the port nearest to the leading edge on the pressure side.

In addition to the synchronous peaks, the dominant feature in the spectra is the pressure excitation in Fig. 9(a) at position 5 on the suction side. It reaches its maximum of 0.093 at the frequency of $33 \mathrm{E}$, or $3182 \mathrm{~Hz}$. Apparently, this disturbance is related to the broad-band turbulence excitation on the suction side of the blade. It is evident that amplification of this disturbance is a function of inlet Mach number, reduced frequency and incidence. For reduced frequency of 10 and negative incidence, Fig. 9(c), the corresponding peak amplitude is 0.065 at $33 \mathrm{E}$ or $3177 \mathrm{~Hz}$. Note that only at reduced frequency of $10 \mathrm{did}$ the high-frequency pressure fluctuations peak at an integral engine order.

Figure 9 also indicates that while the broad-band turbulent excitation in the higher-frequency range is confined to the 
TABLE $\|$ - TIME-AVERAGE FIRST HARMONICS OF THE UNSTEADY BLADE PRESSURES

\begin{tabular}{|c|c|c|c|c|c|c|c|c|c|c|c|c|c|c|}
\hline \multirow[t]{2}{*}{$M_{1}$} & \multirow[t]{2}{*}{$\omega$} & \multirow[t]{2}{*}{$\boldsymbol{\beta}_{2}$} & \multicolumn{12}{|c|}{ Amplitudes [percent $\rho_{1} U_{1}{ }^{2} / 2$ ] and phase angles [radians] } \\
\hline & & & 0 & 1 & 2 & 3 & 4 & 5 & 6 & 7 & 8 & 9 & 10 & 11 \\
\hline \multirow[t]{12}{*}{0.27} & \multirow[t]{4}{*}{10.00} & \multirow[t]{2}{*}{-2.98} & 13.45 & 10.31 & 4.79 & 4.61 & 4.30 & 1.75 & 5.74 & 6.66 & 4.69 & 1.83 & 4.29 & 8.37 \\
\hline & & & -0.13 & -0.28 & -0.42 & 0.36 & 0.30 & -0.17 & -0.48 & -0.38 & -0.29 & -0.08 & -0.04 & 0.27 \\
\hline & & \multirow[t]{2}{*}{2.98} & 6.57 & 4.94 & 1.21 & 1.12 & 1.49 & 0.90 & 1.02 & 1.23 & 1.86 & 3.14 & 7.25 & 8.89 \\
\hline & & & -0.49 & 0.17 & 0.06 & -0.25 & -0.26 & 0.48 & 0.16 & 0.30 & 0.40 & 0.41 & 0.35 & -0.02 \\
\hline & \multirow[t]{4}{*}{5.00} & \multirow[t]{2}{*}{-3.52} & 33.57 & 24.66 & 12.88 & 4.19 & 3.51 & 9.69 & 19.56 & 20.87 & 19.67 & 18.24 & 24.06 & 14.50 \\
\hline & & & -0.20 & -0.28 & -0.30 & -0.28 & 0.02 & 0.10 & 0.06 & 0.09 & 0.12 & 0.15 & 0.12 & 0.36 \\
\hline & & \multirow[t]{2}{*}{3.52} & 25.77 & 10.25 & 2.46 & 5.46 & 9.38 & 14.45 & 4.89 & 5.04 & 5.25 & 6.88 & 14.97 & 16.73 \\
\hline & & & -0.20 & -0.35 & -0.06 & 0.04 & 0.05 & 0.09 & -0.44 & -0.42 & -0.43 & -0.46 & -0.48 & 0.18 \\
\hline & \multirow[t]{4}{*}{2.50} & \multirow[t]{2}{*}{-5.17} & 29.95 & 13.61 & 5.11 & 2.51 & 2.62 & 3.24 & 11.75 & 13.55 & 14.62 & 16.28 & 23.60 & 12.64 \\
\hline & & & 0.27 & 0.22 & 0.16 & 0.02 & 0.07 & 0.14 & -0.18 & -0.18 & -0.18 & -0.19 & -0.23 & -0.03 \\
\hline & & \multirow[t]{2}{*}{5.17} & 20.17 & 1.76 & 8.98 & 11.70 & 15.78 & 20.12 & 9.28 & 8.82 & 9.08 & 10.27 & 17.15 & 16.32 \\
\hline & & & -0.39 & 0.06 & 0.02 & 0.04 & 0.02 & 0.05 & 0.06 & 0.06 & 0.07 & 0.09 & 0.12 & -0.16 \\
\hline \multirow[t]{12}{*}{0.20} & \multirow[t]{4}{*}{10.00} & \multirow[t]{2}{*}{-3.24} & 12.34 & 10.54 & 6.84 & 4.19 & 1.95 & 1.50 & 5.23 & 4.74 & 3.69 & 2.42 & 4.65 & 8.29 \\
\hline & & & -0.10 & -0.29 & -0.42 & 0.44 & 0.27 & -0.08 & 0.49 & -0.37 & -0.22 & -0.03 & -0.02 & 0.31 \\
\hline & & \multirow[t]{2}{*}{3.24} & 5.43 & 4.01 & 1.61 & 1.13 & 0.79 & 1.06 & 0.89 & 1.17 & 1.77 & 2.73 & 5.82 & 7.26 \\
\hline & & & 0.49 & 0.16 & -0.02 & -0.17 & -0.33 & 0.38 & 0.17 & 0.30 & 0.39 & 0.41 & 0.34 & -0.05 \\
\hline & \multirow[t]{4}{*}{5.00} & \multirow[t]{2}{*}{-3.85} & 35.50 & 22.73 & 10.37 & 3.23 & 2.00 & 5.03 & 12.23 & 15.41 & 16.42 & 16.97 & 23.67 & 14.84 \\
\hline & & & -0.15 & -0.23 & -0.27 & -0.35 & 0.27 & 0.17 & 0.12 & 0.15 & 0.19 & 0.22 & 0.19 & 0.40 \\
\hline & & \multirow[t]{2}{*}{3.85} & 20.39 & 6.63 & 7.19 & 7.12 & 5.85 & 4.03 & 6.11 & 5.91 & 5.84 & 7.55 & 16.20 & 18.86 \\
\hline & & & -0.15 & -0.48 & 0.30 & 0.27 & 0.24 & 0.16 & -0.36 & -0.36 & -0.39 & -0.44 & -0.46 & 0.19 \\
\hline & \multirow[t]{4}{*}{2.50} & \multirow[t]{2}{*}{-4.59} & 32.76 & 14.95 & 5.56 & 1.23 & 1.37 & 2.48 & 9.71 & 11.72 & 13.11 & 15.40 & 23.44 & 10.76 \\
\hline & & & 0.31 & 0.27 & 0.24 & 0.15 & -0.09 & -0.20 & -0.19 & -0.18 & -0.18 & -0.18 & -0.22 & -0.03 \\
\hline & & \multirow[t]{2}{*}{4.59} & 13.26 & 8.52 & 11.58 & 11.88 & 11.48 & 10.80 & 4.67 & 5.18 & 6.27 & 8.36 & 15.56 & 17.21 \\
\hline & & & -0.37 & 0.18 & 0.13 & 0.14 & 0.11 & 0.09 & 0.13 & 0.12 & 0.12 & 0.13 & 0.17 & -0.15 \\
\hline
\end{tabular}

suction side at the inlet Mach number of 0.27 , it is also significant on the pressure side at Mach 0.2. The peak excitation at the inlet Mach number of 0.2 in Fig. 9(d) has amplitude of 0.034 and frequency of $39.125 \mathrm{E}$ or $2815 \mathrm{~Hz}$. (Note that the rotational speed was lower for this Mach number.)

The RMS pressure spectra for the clean-inlet case (i.e., no rotor) and the inlet Mach numbers of 0.27 and 0.2 are shown in Fig. 10. For the Mach number of 0.27 , the spectrum corresponds to port 5. The low-frequency peak amplitude is 0.0406 at the frequency of $138.9 \mathrm{~Hz}$. The two high-frequency peaks have amplitudes of 0.0510 and 0.0496 at the corresponding frequencies of 3220 and $3359 \mathrm{~Hz}$. For the cleaninlet Mach number of 0.2 the spectrum corresponds to port 4 (for which it was maximum). The low- and high-frequency peak amplitudes and frequencies are 0.03408 and $138.9 \mathrm{~Hz}$, and 0.0223 and $2807.6 \mathrm{~Hz}$.

The clean-inlet results together with forced excitation results for the entire test matrix show that under forced excitation there is a small frequency shift for the peak high-frequency turbulence excitation relative to the clean inlet. The peak-response frequency is mainly a function of Mach number. The highest magnification factor of pressure fluctuations under forced excitations is about 2. It occurs at a reduced frequency of 10 and positive incidence at an integral engine order frequency. Within the range of gust amplitudes encountered in the test, the gust amplitude does not strongly influence the peak response, since it occurred at a reduced frequency for which the gust amplitude was the smallest. In no case was the amplitude of the pressure fluctuations under forced excitation lower than the corresponding clean-inlet amplitude.

Note that, although there is no indication of separation (i.e., no flattening of $\mathrm{C}_{\mathrm{p}}$ distribution) on the suction side of the blade for the conditions of Fig. 9(a), (see Fig. 4), if the flow separates past the last measuring station on the suction surface, the observed magnification of random pressures in Fig. 9(a) may result because of proximity of separation point, as observed by Shultz et al. (1990).

Since both the dc and ac components of the dynamic pressure were recorded, one can derive the average pressure distribution from the dynamic pressure measurements and compare it to the mean pressure distribution obtained with the steady-state-type instrumentation. This is illustrated in Fig. 11 for the reduced frequency of 5, the inlet Mach number of 0.27 and the negative incidence. The slightly higher values of pressures (and hence the lower values of the negative pressure coefficient in Fig.11) 
in the aft portion of the blade on the suction side are probably caused by the small differences in the blade contours between the steady-state and the dynamically instrumented blades, and the contribution due to the turbulence (Mattingly, 1983). These results are typical for majority of the test conditions.

\section{Wake Turbulence}

Wake turbulent velocity fluctuations are included in the paper because it is possible that some of the observed behavior in the experimental results depends on the turbulence level in the wake. Figures 12 to 14 present the mean-square distribution of turbulent velocities. The Reynolds stress component uv, is small for all conditions and $\mathrm{v}^{2}$ appears to be significantly higher than $u^{2}$ at reduced frequency of 10 . (Without explicit notation, it is implied in the paper, that all second order velocity parameters are mean-square values averaged over about 200 revolutions.) Moreover, at this reduced frequency $u^{2}$ and $v^{2}$ are out phase. At reduced frequencies of 5 and 2.5 these two components are more nearly equal and more nearly in phase.

At reduced frequency of 2.5 (Fig.14) there are periods of low turbulence intensity because the wakes did not merge. The turbulence intensity between the wakes corresponds to free stream turbulence. Perhaps the previously noticed steep unsteady pressure variation in the forward part of the blade suction surface (port 1) for $\omega=2.5, \beta_{2}>0$, and $M_{1}=0.27$ arises because the prolonged periods of high- and low-turbulenceintensity fluctuations may influence the unsteady flow structure in this region. Some support for this argument follows from the work of Liu and Rodi (1991), who noticed that the transition point is frequency dependent for wakes that have not merged. It appears that for non-sinusoidal gust, it would be valuable to include detailed boundary layer measurements in addition to the unsteady pressure. If there is a separation bubble in the region of this pressure port at the stated conditions, one would expect a low value of the unsteady-pressure amplitude according to Schulz et al. (1990).

\section{CONCLUDING REMARKS}

For the two-out-of-three reduced frequencies in the experiment, a nearly sinusoidal gust has been generated allowing a parametric study of the reduced frequency effects in the time and frequency domains. The incidence variation at each reduced frequency was accomplished without a change in the inlet Mach number or the flow coefficient. The gust amplitude varied somewhat with the reduced frequency; however, it did not appear to have a dominant effect.

Unsteady, synchronous-response blade pressures are strongly dependent on reduced frequency and incidence. Mach number dependence is weak for negative incidence and significant for positive incidence at lower reduced frequencies.

The mean blade-pressure distribution is to some extent dependent on the reduced frequency, particularly for the negative incidence and the higher inlet Mach number.
At the reduced frequency of 10 , the inlet Mach number of 0.27 , and the positive incidence, a magnification of the turbulent pressure fluctuations on the suction side of the aft portion of the blade resulted in a significant excitation concentrated at an integral engine order much higher than the synchronous excitation frequency.

\section{REFERENCES}

Bruun, H. H., 1990, "Signal Analysis Method of X Hot- Wire Anemometry," in "The Heuristics of Thermal Anemometry," Proceedings of ASME Fluids Engineering Division, D.E. Stock, et al.,ed.,FED- 97, Toronto, Canada, pp53-58

Fujita, H., and Kovasznay, S.G., 1968, "Measurement of Reynolds Stress by a Single Rotated Hot Wire Anemometer," The Review of Scientific Instruments, Vol. 39, pp1352-1355.

Kurkov, A.P., and Mehmed, O., 1993, "Optical Measurement of Unducted Fan Flutter," ASME Journal of Turbomachinery, Vol. 115, pp.189-196.

Liu, X., and Rodi, W., 1991, "Experiments on Transitional Boundary Layers with Wake-Induced Unsteadiness," Journal of Fluid Mechanics, Vol. 231, pp.229-256.

Manwaring, S. R., and Wisler, D. C., 1993, "Unsteady Aerodynamics and Gust Response in Compressors and Turbines," ASME Journal of Turbomachinery, Vol. 115, pp.724-740.

Mattingly, G. E., "Volume Flow Measurements," in "Fluid Mechanics Measurements," R. J. Goldstein, ed. Hemisphere Publishing Co., New York, N.Y., 1983.

Rabiner, L.R., and McGonegal, C.A., 1979, "FIR Windowed Filter Design Program-WINDOW," in "Programs for Digital Signal Processing," IEEE Press, New York, NY.

Schulz, H. D., Gallus, H. E., and Lakshminarayana, B., 1990, "Three-Dimensional Separated Flow Field in the Endwall Region of an Annular Compressor Cascade in the Presence of Rotor-Stator Interaction: Part 2 - Unsteady Flow and Pressure Field," ASME Journal of Turbomachinery, Vol. 112, pp .679688. 
APPENDIX - BLADE AND PRESSURE-PORT COORDINATES

TABLE IA - BLADE COORDINATES

\begin{tabular}{|c|c|c|c|c|c|c|c|c|c|c|c|c|c|c|}
\hline$x_{L}$ & 0.000 & 0.050 & 0.100 & 0.150 & 0.200 & 0.250 & 0.300 & 0.350 & 0.400 & 0.450 & 0.500 & 0.550 & 0.600 & 0.650 \\
\hline$Y_{L}$ & 0.192 & 0.063 & 0.023 & 0.005 & 0.000 & 0.009 & 0.021 & 0.034 & 0.046 & 0.057 & 0.068 & 0.079 & 0.090 & 0.099 \\
\hline$x_{L}$ & 0.700 & 0.750 & 0.800 & 0.850 & 0.900 & 0.950 & 1.000 & 1.050 & 1.100 & 1.150 & 1.200 & 1.250 & 1.300 & 1.350 \\
\hline$Y_{L}$ & 0.109 & 0.118 & 0.126 & 0.134 & 0.141 & 0.148 & 0.154 & 0.160 & 0.164 & 0.168 & 0.172 & 0.174 & 0.176 & 0.178 \\
\hline$X_{L}$ & 1.400 & 1.450 & 1.500 & 1.550 & 1.600 & 1.650 & 1.700 & 1.750 & 1.800 & 1.850 & 1.900 & 1.950 & 2.000 & 2.050 \\
\hline$Y_{L}$ & 0.178 & 0.178 & 0.176 & 0.174 & 0.172 & 0.168 & 0.164 & 0.159 & 0.153 & 0.146 & 0.138 & 0.130 & 0.121 & 0.111 \\
\hline$X_{L}$ & 2.100 & 2.150 & 2.200 & 2.250 & 2.300 & 2.350 & 2.400 & 2.442 & 2.450 & 2.489 & -a----- & - -------- & -........ & ---...-. \\
\hline$Y_{L}$ & 0.100 & 0.088 & 0.076 & 0.062 & 0.048 & 0.033 & 0.017 & 0.003 & 0.000 & 0.034 & -...-..- & - - - & $-\cdots-\cdots$ & --.--..- \\
\hline$x_{u}$ & 0.000 & 0.042 & 0.050 & 0.100 & 0.150 & 0.200 & 0.250 & 0.300 & 0.350 & 0.400 & 0.450 & 0.500 & 0.550 & 0.600 \\
\hline$Y_{u}$ & 0.192 & 0.312 & 0.321 & 0.384 & 0.431 & 0.469 & 0.499 & 0.525 & 0.546 & 0.563 & 0.577 & 0.589 & 0.597 & 0.604 \\
\hline$x_{u}$ & 0.650 & 0.700 & 0.750 & 0.800 & 0.850 & 0.900 & 0.950 & 1.000 & 1.050 & 1.100 & 1.150 & 1.200 & 1.250 & 1.300 \\
\hline$Y_{u}$ & 0.609 & 0.612 & 0.613 & 0.613 & 0.611 & 0.608 & 0.604 & 0.599 & 0.592 & 0.585 & 0.576 & 0.567 & 0.556 & 0.545 \\
\hline$x_{u}$ & 1.350 & 1.400 & 1.450 & 1.500 & 1.550 & 1.600 & 1.650 & 1.700 & 1.750 & 1.800 & 1.850 & 1.900 & 1.950 & 2.000 \\
\hline$Y_{u}$ & 0.532 & 0.519 & 0.505 & 0.490 & 0.475 & 0.459 & 0.442 & 0.424 & 0.405 & 0.386 & 0.366 & 0.346 & 0.324 & 0.302 \\
\hline$x_{u}$ & 2.050 & 2.100 & 2.150 & 2.200 & 2.250 & 2.300 & 2.350 & 2.400 & 2.450 & 2.472 & 2.489 & -ביב- & -........ & ------ \\
\hline$Y_{u}$ & 0.279 & 0.256 & 0.232 & 0.207 & 0.182 & 0.156 & 0.130 & 0.103 & 0.075 & 0.063 & 0.034 & - & -------. & - \\
\hline
\end{tabular}

TABLE IIA - STEADY-STATE PRESSURE PORT LOCATIONS (FIGURE 2)

\begin{tabular}{|l|l|l|l|l|l|l|l|l|l|l|l|}
\hline$X_{L}$ & 0.000 & 0.058 & 0.188 & 0.312 & 0.502 & 0.748 & 0.999 & 1.247 & 1.491 & 1.745 & 1.995 \\
\hline$X_{U}$ & 0.000 & 0.063 & 0.188 & 0.300 & 0.490 & 0.743 & 0.995 & 1.246 & 1.496 & 1.747 & 1.991 \\
\hline
\end{tabular}

TABLE IIIA - DYNAMIC PRESSURE PORT LOCATIONS (FIGURE 2)

\begin{tabular}{|c|c|c|c|c|c|c|}
\hline PORT & 11 & 10 & 9 & 8 & 7 & 6 \\
\hline$X_{L}$ & 0.039 & 0.247 & 0.500 & 0.873 & 1.248 & 1.621 \\
\hline PORT & 0 & 1 & 2 & 3 & 4 & 5 \\
\hline$X_{U}$ & 0.119 & 0.499 & 0.879 & 1.256 & 1.629 & 2.005 \\
\hline
\end{tabular}

rotating pins

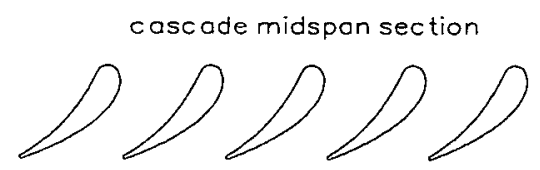

Fig. 1 ROTOR-STATOR CONFIGURATION

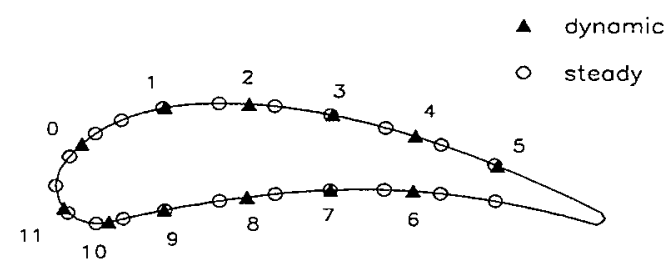

Fig.2 INSTRUMENTATION PORTS 

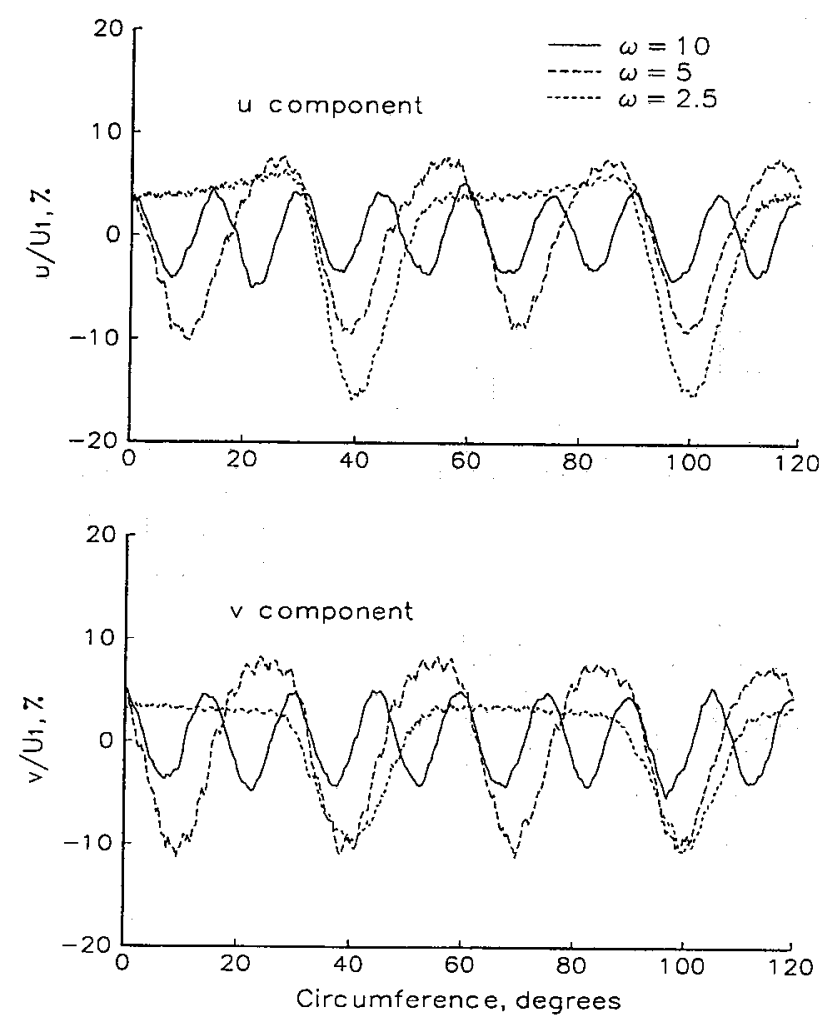

Fig. 3 INLET VELOCITY PROFILES, $M_{1}=0.27$
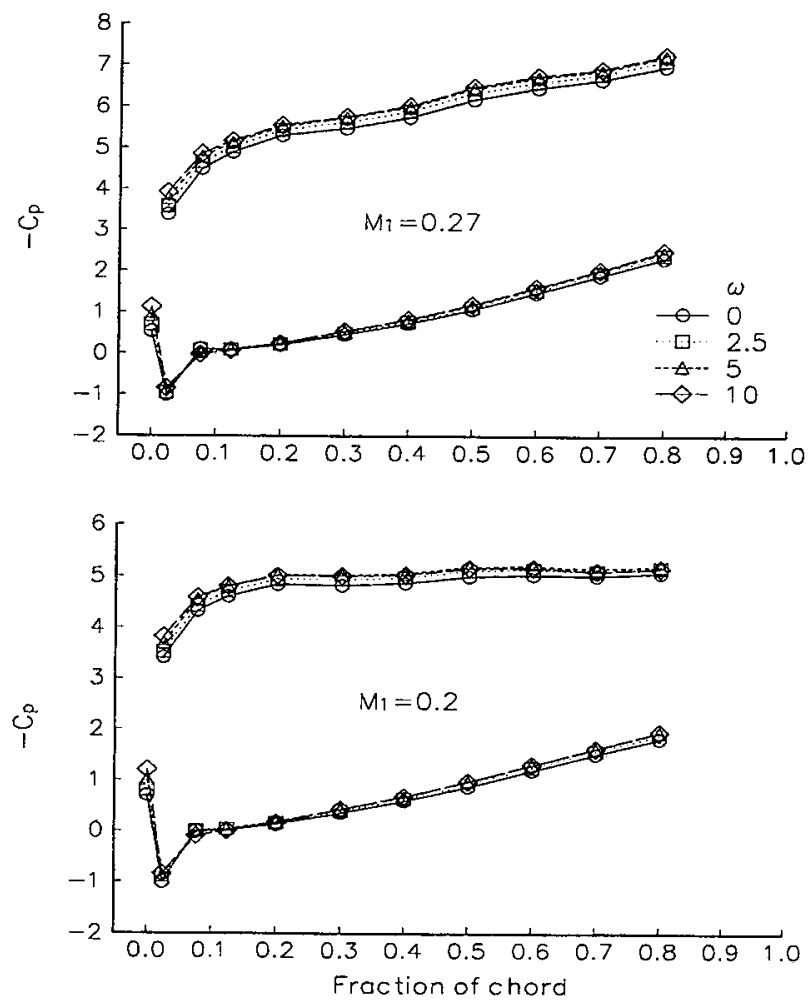

Fig. 4 MEAN PRESSURE COEFFICIENTS, $\beta_{2}>0$
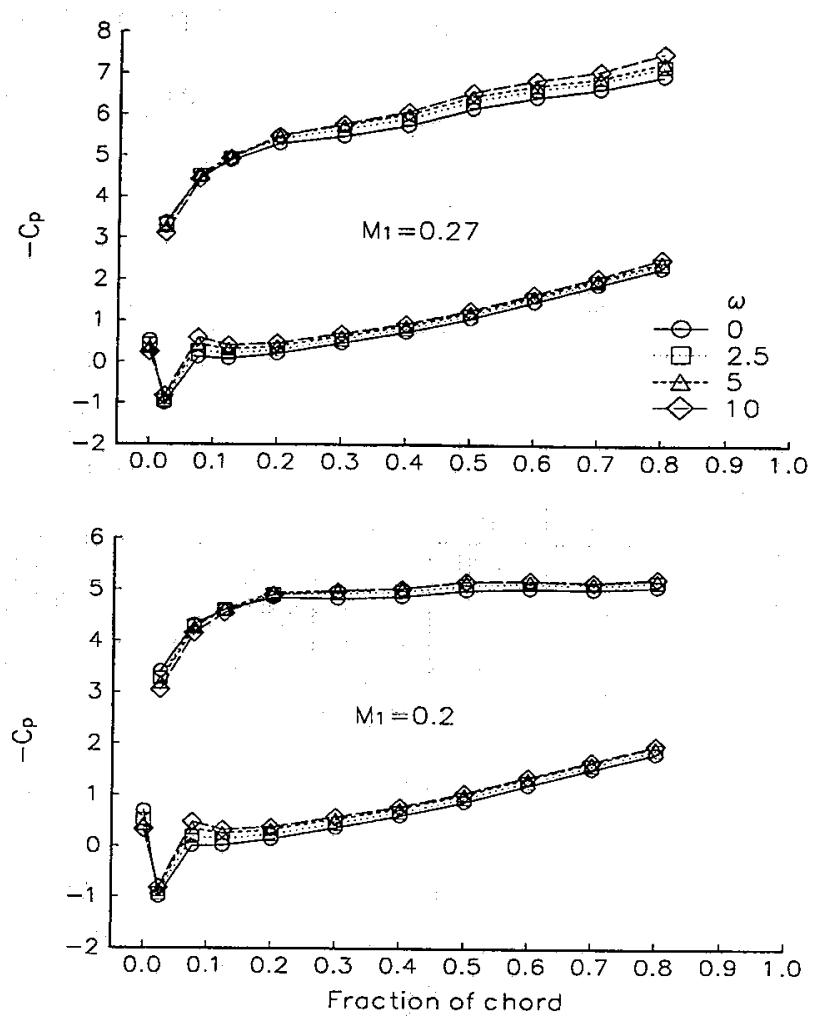

Fig. 5 MEAN PRESSURE COEFFICIENTS, $\beta_{2}<0$
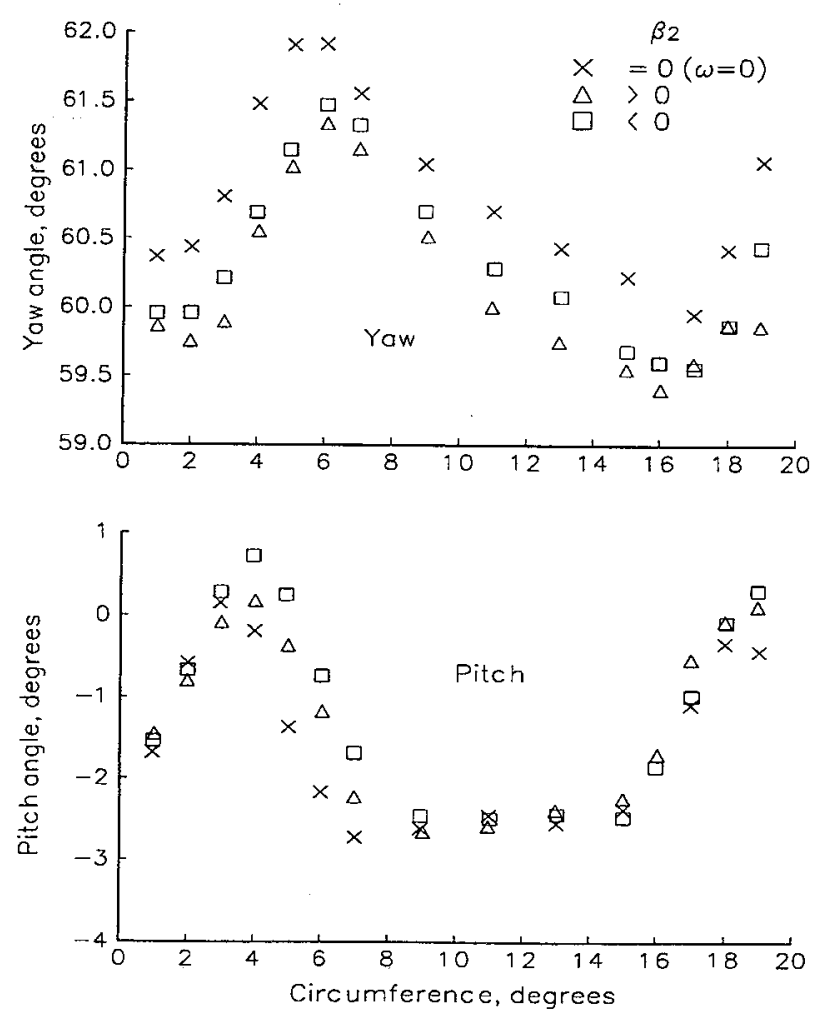

Fig. 6 EXIT ANGLES, $\omega=10, M_{1}=0.27$ 


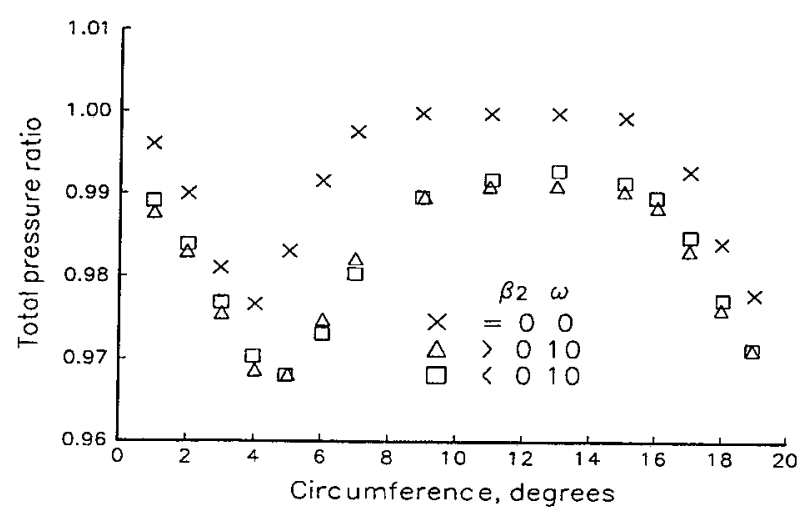

Fig. 7 EXIT TOTAL PRESSURE RATIO, $M_{1}=0.27$
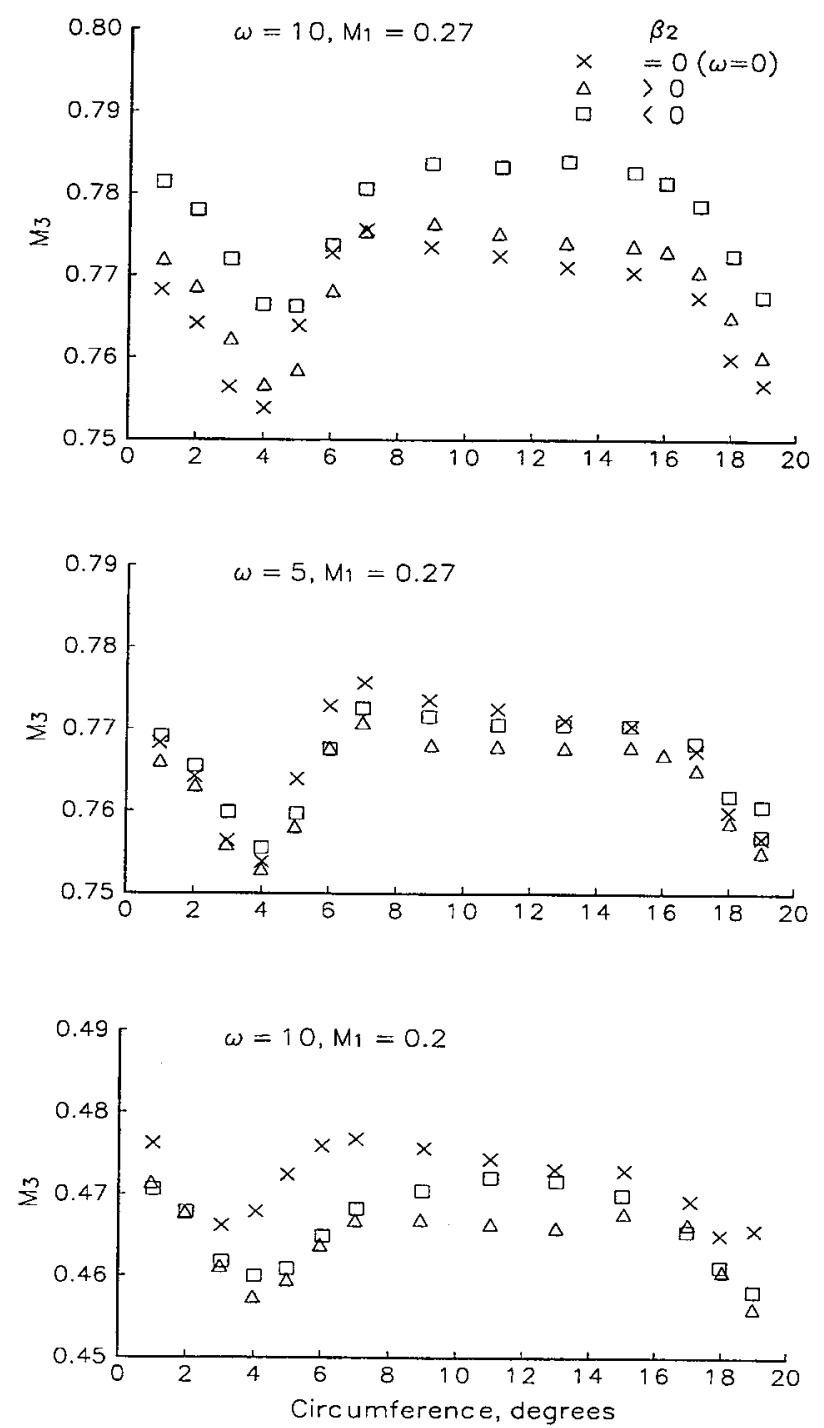

Fig. 8 EXIT MACH NUMBER

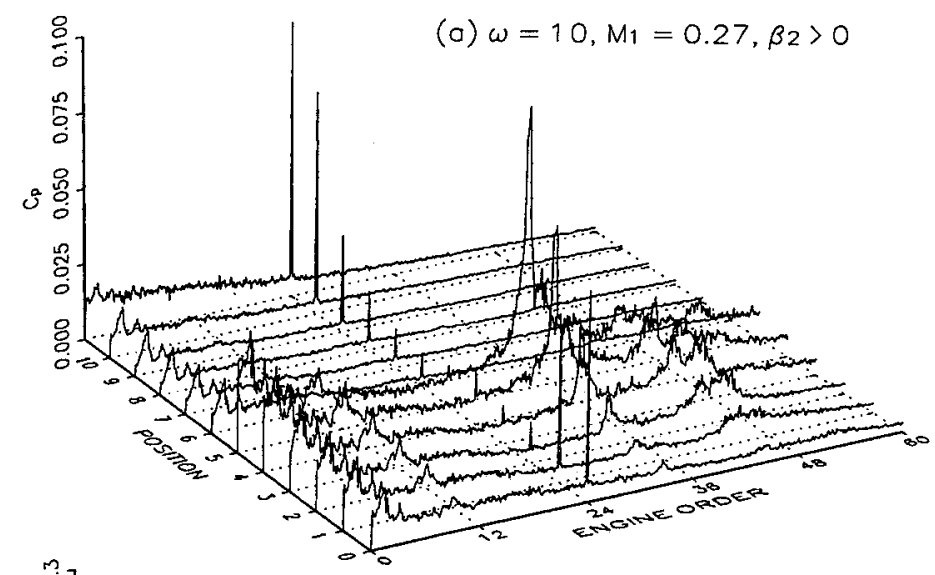

(b) $\omega=5, M_{1}=0.27, \beta_{2}>0$

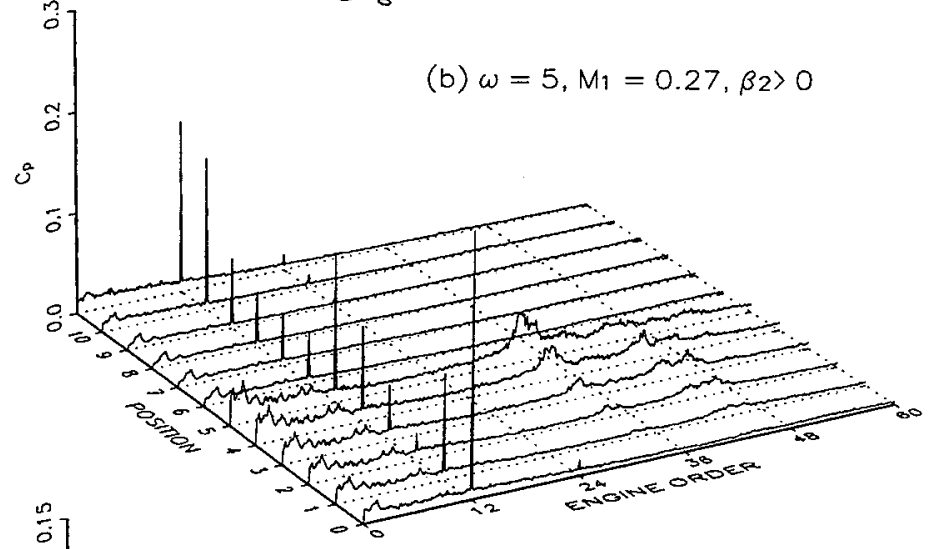

(c) $\omega=10, M_{1}=0.27, \beta_{2}<0$
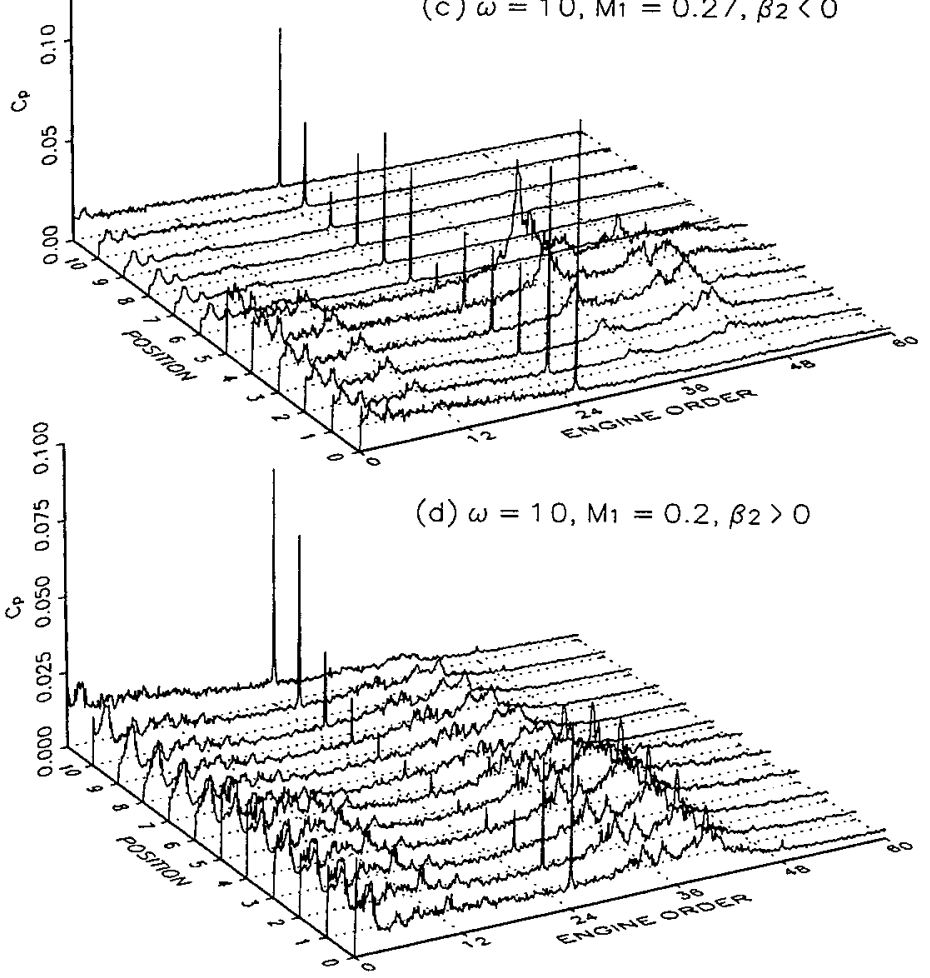

Fig. 9 RMS PRESSURE SPECTRA 


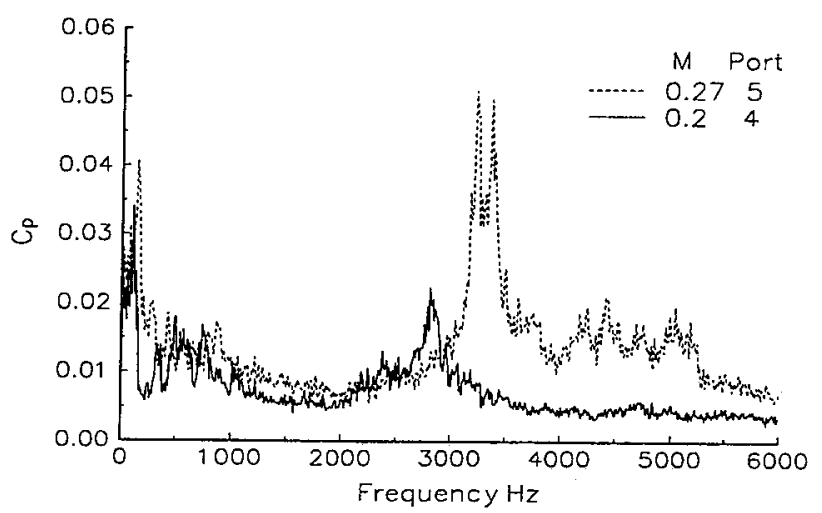

Fig. 10 CLEAN INLET RMS PRESSURE SPECTRA

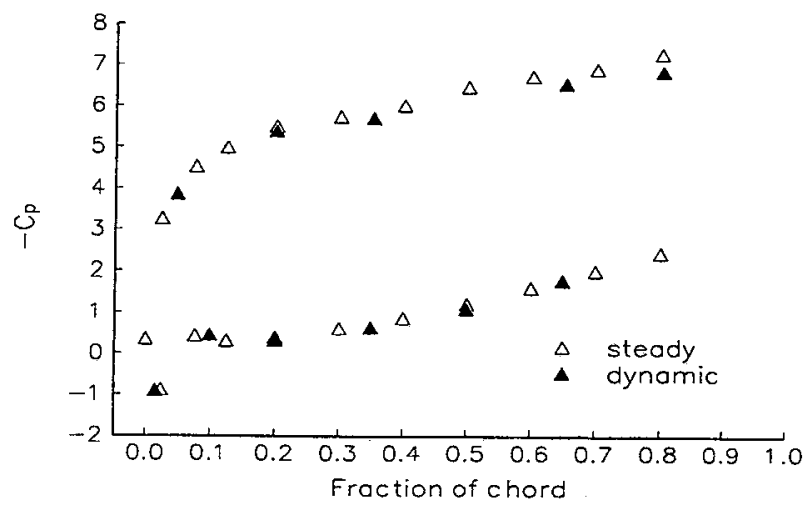

Fig. 11 MEAN PRESSURES, $M_{1}=0.27, \omega=5, \beta_{2}<0$
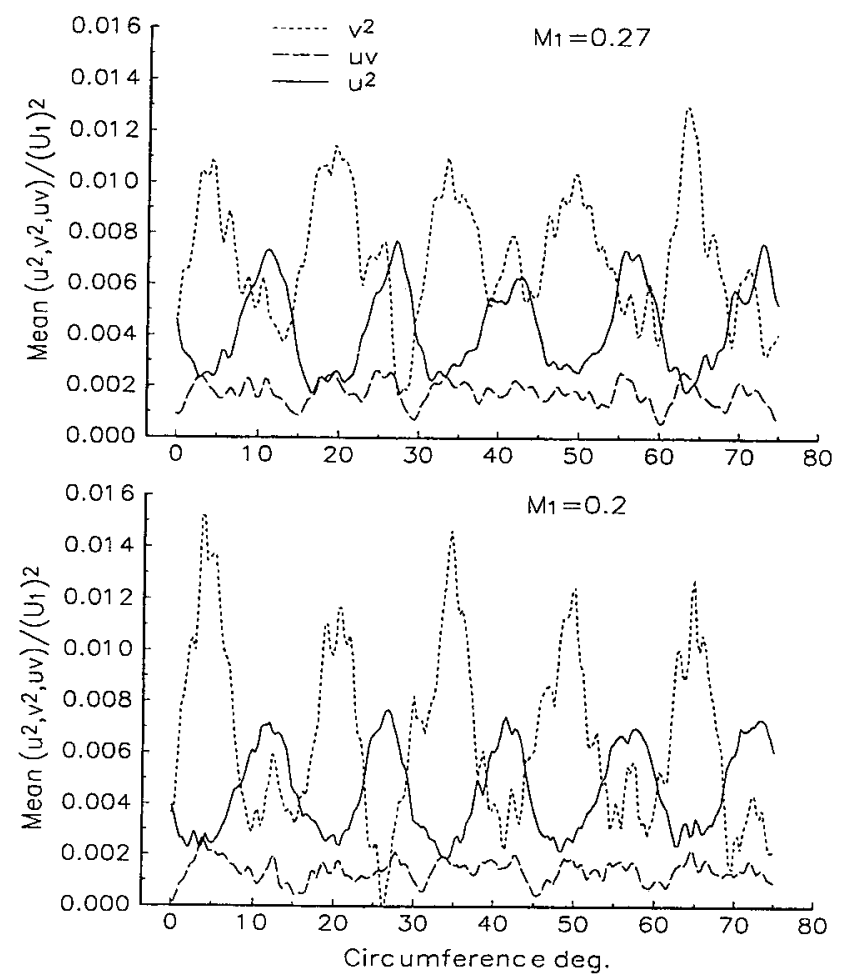

Fig. 12 MEAN-SQUARE FLUCTUATING VELOCITIES, $\omega=10$
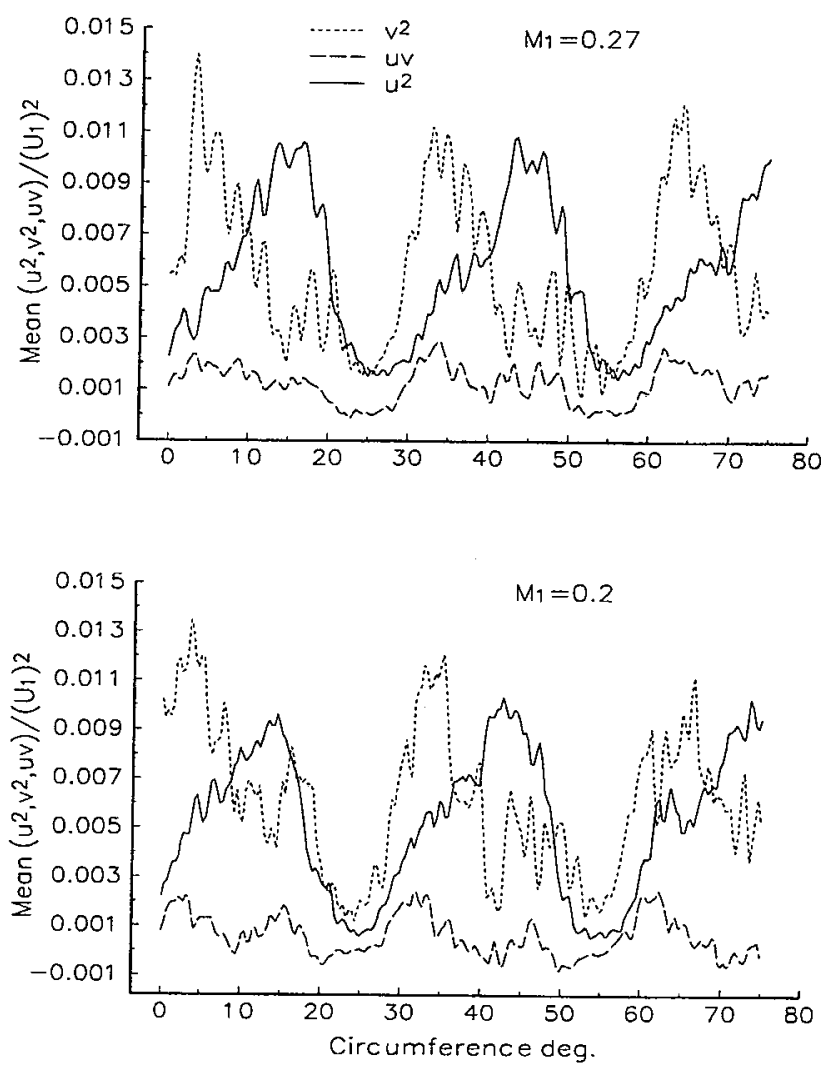

Fig. 13 MEAN-SQUARE FLUCTUATING VELOCITIES, $\omega=5$
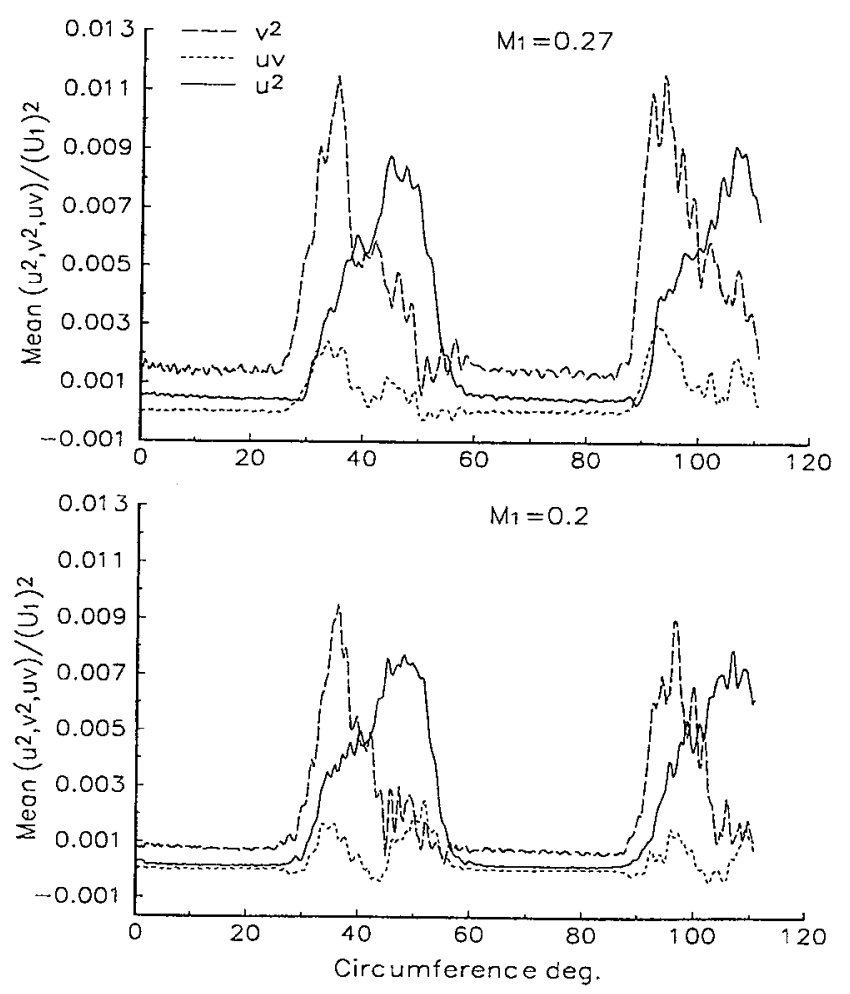

Fig. 14 MEAN-SQUARE FLUCTUATING VELOCITIES, $\omega=2.5$ 


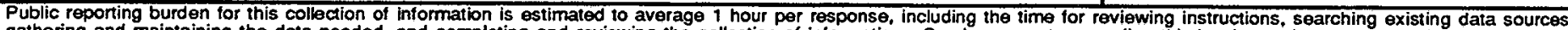

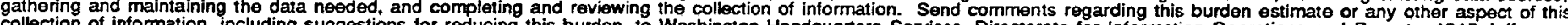

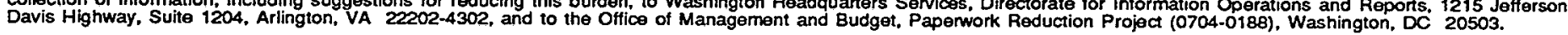
1. AGENCY USE ONLY (Leave blank)
2. REPORT DATE
January 1995
3. REPORT TYPE AND DATES COVERED

4. TITLE AND SUBTITLE

Measurement of Gust Response on a Turbine Cascade 5. FUNDING NUMBERS

6. AUTHOR(S)

WU-505-63-5B

A.P. Kurkov and B.L. Lucci

7. PERFORMING ORGANIZATION NAME(S) AND ADDRESS(ES)

National Aeronautics and Space Administration

Lewis Research Center

Cleveland, Ohio 44135-3191

8. PERFORMING ORGANIZATION

REPORT NUMBER

E-9227

9. SPONSORING/MONITORING AGENCY NAME(S) AND ADDRESS(ES)

10. SPONSORING/MONITORING

National Aeronautics and Space Administration

Washington, D.C. 20546-0001

AGENCY

NASA TM-106776

11. SUPPLEMENTARY NOTES

Prepared for the Turbo Expo '95 sponsored by The American Society of Mechanical Engineers, Houston, Texas, June 5-8, 1995. Responsible person, A.P. Kurkov, organization code 5230, (216) 433-5695.

12a. DISTRIBUTION/AVAILABILITY STATEMENT

Unclassified - Unlimited

Subject Category 02

13. ABSTRACT (Maximum 200 words)

The paper presents benchmark experimental data on a gust response of an annular turbine cascade. The experiment was particularly designed to provide data for comparison with the results of a typical linearized gust-response analysis.

Reduced frequency, Mach number, and incidence were varied independently. Except for the lowest reduced frequency, the gust velocity distribution was nearly sinusoidal. For the high inlet-velocity series of tests, the cascade was near choking. The mean flow was documented by measuring blade surface pressures and the cascade exit flow. High-response pressure transducers were used to measure the unsteady pressure distribution. Inlet-velocity components and turbulence parameters were measured using hot wire. In addition to the synchronous time-average pressure spectra, typical power spectra are included for several representative conditions.

14. SUBJECT TERMS

Forced response; Gust; Wakes

17. SECURITY CLASSIFICATION OF REPORT

Unclassified
18. SECURITY CLASSIFICATION OF THIS PAGE Unclassified
19. SECURITY CLASSIFICATION OF ABSTRACT Unclassified 